\title{
Staff Development in Western Canadian Colleges
}

\author{
Abram G. Konrad *
}

The majority of post-secondary non-university institutions in western Canada were established during the 1960 's. Although program dimensions vary considerably among these institutions, they can be regarded as community colleges in that they purport to serve the needs of post high school or adult students in "local" communities.

The rapid rise and unique thrust of community colleges in western Canada has focused on several developmental issues, not the least of which relates to staffing. Where do these post-secondary non-university institutions secure qualified faculty? What constitutes appropriate preparation for college teaching ? Where is such preparation obtained ? Should standard requirements be identified and minimum preparation programs recognized through the establishment of certification procedures ? These questions must concern those responsible for community college developments.

None of the western provinces has established minimum requirements for teaching appointments in community colleges. And even if they had, staff development needs would still have to be considered in meeting the institutional commitment to teaching and learning. Staff development must be regarded as more than a stop-gap method of upgrading faculty who are inadequately prepared for college teaching; it should be an essential component of the personnel policy in every educational institution, particularly in the community college with its avowed commitment to teaching.

A survey of the writings on staff development suggests considerable variation in the scope of this topic. Some writers conceive of staff development narrowly as inservice training; others take a broad view and include everything that effects change in the instructional program, including organizational development. The survey which is reported here is premised on the assumption that staff development is any activity that enhances the effectiveness of staff.

* Dr. A.G. Konrad is a member of the College Administration Project and Associate Professor of Educational Administration, The University of Alberta. 


\section{Survey Procedure}

Thirty-one colleges in western Canada recently participated in a survey of staff development practices. ${ }^{1}$ A brief one-page questionnaire was mailed to thirty-four postsecondary non-university institutions, including all public community colleges and private colleges offering transfer programs in the four western provinces. In addition to gathering some descriptive information, the survey was designed to determine the nature of staff development programs in these institutions and to identify major problems associated with these programs.

No efforts were made to develop comprehensive instrumentation, nor to identify all of the variables relevant to this topic. It was recognized, however, that the exploratory nature of the study could result in more rigorous research efforts in this area in the future. ${ }^{2}$ This report describes some of the common elements and problems in college staff development programs. ${ }^{3}$

\section{What Is Staff Development?}

Twenty-four colleges, or $77 \%$ of the post-secondary non-university institutions responding to this questionnaire, have faculty development programs. The respondents each listed three major objectives of staff development programs in their institutions. These responses were read carefully in an attempt to develop classification categories. While some responses were difficult to categorize, the following classification emerged: orientation, in-service training, professional development, and organizational development. Although the classification categories are not mutually exclusive, every effort was made to make the classification as meaningful as possible.

Table I shows a distribution of staff development objectives identified by the colleges. Responses of some institutions appeared to be duplicative, thus accounting for more than 31 entries in two of the categories. Indeed, some respondents identified more than three objectives, resulting in a total number of responses in excess of 93 or three per institution.

Table I

MAJOR OBJECTIVES OF STAFF DEVELOPMENT

\begin{tabular}{lcc}
\multicolumn{1}{c}{ Objective } & Frequency & $\%$ \\
Orientation & 13 & 11.3 \\
In-service training & 53 & 46.1 \\
Professional development & 48 & 41.7 \\
Organizational development & 1 & 0.9 \\
\cline { 2 - 2 } & 115 & 100.0
\end{tabular}


Orientation. Only $11 \%$ of the institutional responses identified orientation as a major objective of staff development programs. According to the respondents, preservice or orientation sessions are designed to assist faculty to understand and accept the basic philosophy, role and functioning of an institution, and to clarify the conditions of employment for the faculty. Orientation sessions are especially helpful to new faculty. They usually precede the first assignment of the faculty, although some institutions extend these sessions into the regular academic year. Most institutions conduct orientation sessions on campus, although a few colleges hold faculty retreats off-campus just prior to the beginning or at the end of an academic year.

In-service training. Almost half of the total number of responses were categorized as meeting in-service training objectives. The objectives of in-service training are concerned with the improvement of teaching and learning. This category includes issues related to curriculum development, instructional methodologies, evaluation procedures and interpersonal relationships. Activities that are commonly employed for in-service training include staff meetings, seminars, demonstrations, programmed study materials, simulation and supervised practice. Most in-service programs are conducted on campus by college personnel, although consultants and guest speakers occasionally are used for specialized tasks.

Professional development. Objectives related to professional development were identified by $42 \%$ of the responses. Continuing education or professional development seeks to enable staff members to keep abreast of the advancement of knowledge, both in their specialty and in general. Professional development focuses primarily on the faculty individually. Typical activities include professional reading, attendance at professional conferences, industrial tours, work experience, study leaves, and membership in professional organizations and committees.

Organizational development. Only one respondent identified an objective for staff development that focused on the total college environment. Organizational development could effect an improvement in the faculty through re-structuring or re-grouping persons and positions within an institution.

In-service training and professional development objectives are emphasized predominantly in staff development programs of the community colleges in western Canada. It may be interesting to speculate on the reasons for such an emphasis, particularly in the light of the newness of these institutions. Are problems more common to one type of activity than to another?

\section{What Are the Major Problems?}

The questionnaire asked respondents to identify three of the most pressing problems in staff development. Since not all institutions identified three distinct problems fewer than 93 responses are tabulated in Table II. A high degree of interrelatedness 
exists among the problem categories reported in Table II and, therefore the listing is best viewed as a summary of problems encountered in staff development programs.

Table II

MAJOR PROBLEMS IN STAFF DEVELOPMENT

\begin{tabular}{lcc}
\multicolumn{1}{c}{ Type of Problem } & Frequency & $\%$ \\
Program concerns & 23 & 29.5 \\
Staff attitudes & 21 & 26.9 \\
Financial matters & 12 & 15.4 \\
Time constraints & 12 & 15.4 \\
Replacement of staff & 6 & 7.7 \\
Geographical location & 2 & 2.6 \\
Legal restrictions & 1 & 1.3 \\
Space limitations & 1 & 1.3 \\
\hline & 78 & 100.1
\end{tabular}

Program concerns. Almost one-third of the problems identified in this survey relate to the designing and availability of suitable programs for staff development. Some institutions develop their own programs ; others expect to import or adopt "ready-made" staff development programs from major universities or educational research and development centers. Imaginative programs that meet the specific needs of a faculty are diffcult to develop, particularly if only minimal support is available. On the other hand how can faculty, either individually or in groups, locate materials that will meet their needs?

Staff attitudes. Another persistent problem in staff development encountered by community colleges lies in the attitude of staff toward such programs. Faculty development programs are a threat to the status quo. Some faculty resist change almost at all costs. For them, participation in a seminar on innovative teaching, for example, is tantamount to an acknowledgement of inadequacy. The great range of faculty ability and interest complicates matters further. What strategies can be used to redirect staff attitudes so that participation will occur?

Fiscal and time constraints. Time and money matters each account for fifteen per cent of the problems in staff development programs. Who pays for specific programs is a major concern to colleges. How can cost-benefits be determined for such a variety of approaches to staff development? Should faculty development policy become a part of the contractual agreement? Perhaps faculty would be willing for a larger portion of direct costs if appropriate incentives were developed. For example, institutions might provide for released time or a reduced load to encourage greater participation in programs. 
Otber factors. A variety of other factors were identified as problem areas in staff development. Most of these could be related to the area of program concerns, staff attitudes, and fiscal and time constraints, but they are listed separately in Table II in an attempt to provide greater specificity in the report. Replacing staff on study leaves and proximity to a major educational industrial center may be problems more peculiar to smaller institutions remotely located. Legal and space restrictions were each listed only once as problems in staff development.

\section{Some Reflections on Staff Development}

An exploratory study of this kind often raises more questions than it answers. While the data do not permit rigorous analysis, the descriptive information does serve to identify several concerns in staff development.

1. What is the effect of institutional size and type on staff development programs? Are orientation activities less important to smaller colleges than they are to larger institutions ? Do some colleges give top priority to objectives related to in-service training and other institutions to professional development? Do certain problems emerge more frequently in one type of institutions than in another?

2. How is a staff development program best administered? The questionnaire asked for an identification. of the officer responsible for staff development within the institution. No systematic pattern emerged for institutions with an enrolment below one thousand. In larger colleges, however, it was most common to find a second-level administrator responsible for this function. Do program objectives vary from one administrative arrangement to another? How are faculty best involved in planning and conducting staff development programs? Can students contribute to faculty growth ?

3. What kinds of support do staff development programs receive? A perusal of the responses showed that institutions carried the full cost of programs most commonly when the objectives related to orientation and in-service training. Continuing education or professional development costs were shared or carried exclusively by participants about half of the time. Does this variation in support reflect institutional biases in program objectives ? Is one type of activity more effective than another and, therefore, deserving more support? What percentage of the budget should be allocated to staff development? If staff development programs are designed to upgrade faculty, how equitable is a program that focuses more directly on the needs of the less-qualified than on the better-qualified faculty? What provisions should be made to release faculty in whole or in part for professional growth experiences?

\section{Conclusion}

Staff development functions are served in one manner or another at most of the post-secondary non-university institutions of western Canada. Programs have been de- 
signed to meet objectives in faculty orientation, in-service training, and professional development. Organizational development is rarely identified as an approach to staff development. Problems most frequently encountered relate to program concerns, staff attitudes, and fiscal and time constraints.

The strong commitment of community colleges to meet local needs through instructional programs predisposes them to strive for high quality teaching. Some faculties are well prepared to meet these expectations; others require substantial assistance. Whether staff development occurs by informal means or through structured programs matters less than that conscious efforts are applied to make faculty competent in their task performance.

Notes

1. The survey was undertaken, in part, to gather descriptive information in preparation for a staff development workshop in June 1972 in Vancouver, B.C., sponsored by the College Administration Project with the support of The W.K. Kellogg Foundation. Jack Wood, a graduate student in educational administration, assisted in the analysis of the questionnaire.

2. Two doctoral dissertation studies on specific aspects of faculty development in community colleges in western Canada are now in progress at the Department of Educational Administration, The University of Alberta.

3. This report focuses on the two central concerns of the survey: "What are the three major objectives of your program ?" and "Identify three of the most pressing problems in faculty development." 